\title{
Friday Cleaning Campaign FCC as Community Based initiative of Community Engagement in Health Promotion
}

\author{
Said Habib* \\ Director of Non Communicable Diseases (NCD), Ministry of Public Health Afghanistan, Afghanistan
}

Received: September 21, 2017; Published: October 05, 2017

*Corresponding author: Said Habib, Director of Non Communicable Diseases (NCD), Control Program Senior Advisor for PHC / CBHC, Ministry of Public Health, Afghanistan

\section{Opinion}

MoPH Afghanistan with my leadership piloted two "best practices" (Integrated Health Post and Friday Cleaning Campaign) in 4 provinces (Kabul, Herat, Jawzjan and Nangarhar) for one year (2011-2012). These two best practices were observed during a study tour of Indonesia and Bangladesh and were determined to be feasible in the context of Afghanistan as well as having the potential for a significant impact. Both Indonesia and Bangladesh have wellestablished community-based health care a program from which there is much to learn.

The main purpose of this project was to promote healthy lifestyles through community involvement and empowerment. The project goal is to contribute to the reduction of maternal and child mortality and morbidity through families adopting best practices that promote healthy behaviors in the community. The objectives of project were to increase access to basic health services(ANC, delivery plan, PNC, F.P, GMP, ,ORT corner, and effective referral system) at the door site and other to improve health and nutrition status of U5Y children through promoting knowledge of the community in use of essential nutrients and healthy cooking practices in their houses. Other objectives were to document evidence of feasibility of inclusion of such interventions in the national CBHC package, and to promote hygiene and environmental sanitation practices in villages of the related Integrated Health Post IHP by cleaning up the surroundings area twice a month and to decreases risk factors of communicable diseases (diarrhea diseases, intestinal worms, typhoid, malaria, Leishmaniasis, and TB) in intervention sites.

Four teams conducted the assessment and interviewed PPHOs, NGOs, CBHC officers, health facility staff, CHWs, and community members. After completing the data collection component of the EOP assessment in 4 provinces, the CBHC team then analyzed the data and compiled the report, presented to the MoPH authorities and integrated the Friday cleaning campaigns in to the revised CBHC strategy [1-3].

\section{Integrated Health Posts IHPs}

Health facility staff ( Doctors or Midwives and CHSs) conduct Integrated Health Posts once every month at the home of a CHW in order to provide health services (including treatment of common diseases, antenatal care, postnatal care, family planning, Growth Monitoring Promotion/GMP, hygiene and sanitation , managing ORT corners, and providing appropriate referral). Other activities include displaying fruit and vegetable models as visual aids in health education sessions (done by CHWs) in order to change key health behaviors related to nutrition. As a result of Integrated Health Post activities, CHWs increased their use of medicines by $20 \%$ compared with their use of medicines prior to the IHP pilot program. IEC materials and non medical items like fruit and food models were distributed to selected Health Posts through NGOs implementing the BPHS.

\section{Friday Cleaning Campaign FCC}

Support for village-based Friday Cleaning Campaigns was provided by CHWs together with Community Health Supervisors CHSs and by members of the Shura-e-Sehi. They worked with villagers to identify public areas for cleaning as well as developing an annual schedule for cleaning HP coverage areas and for regularly supervised Friday Cleaning Campaigns supported by CHWs. Communities were invited to gather twice per month for a Friday cleaning campaign by CHWs working through their local Health Shuras (mosques, schools). For this activity the CBHC department of the MoPH distributed tools (wheelbarrows, shovels, pickaxes, pitchforks, and saws) for cleaning of their respective areas.

\section{Conclusion}

Community based health care is a successful program in Afghanistan, which provide primary health care services as close as to the people homes through health posts by two male and female community health worker. For now in Afghanistan, it is the best way 
to reach to the people homes, so it needs to be more strengthened and expanded. Also we should more focus on quality of health care services which provided by health posts. After implementation of pilot FCC project, result was presented to the Technical Advisory Group TAG Ministry of Public Health Afghanistan, result was accepted and decided, this innovation especially Friday Cleaning Campaign FCC should be include in National Package of the Health Service BPHS.

\section{References}

1. Ministry of public Health of Afghanistan, Community Based Health Care National Strategy (2015).

2. Ministry of public Health of Afghanistan, Community Health Workers training manual (2012)

3. Ministry of public Health of Afghanistan, Community Based Health Care Department Documents.

\begin{tabular}{ll}
\hline $\begin{array}{l}\text { BIOMEDICAL } \\
\text { RESEARCHES }\end{array}$ & $\begin{array}{l}\text { Assets of Publishing with us } \\
\text { - Global archiving of articles }\end{array}$ \\
& - Immediate, unrestricted online access \\
\hline
\end{tabular}

